\title{
Psychological injutation collective ethnic and political identity of Ukrainians
}

\begin{abstract}
Introduction: The essence of the problem of psychological inmutation of the collective (ethnic and political) identity of Ukrainians, reflected in the mass-media of Ukraine during the "Home war 2014 year", consists of that, in our view, modern Ukrainians do not have the cored understanding of the personal ethnic auto authentication, and, for Ukrainians she is absent; , for Ukrainians, today.

Methods: We appealed to the content-analyze, that allowed us to specify us sense concepts "Ethnic authentication" and "political authentication". We appealed to the method of questioning in the form of a standardized questionnaire. The methods of generalization and abstracting did not give us the opportunity to make a mistake and were allowed to be distracted from the second-rate details that did not touch the article of our research. At an analysis got during the questionnaire of data, we used a statistical method in form an inquality analysis.
\end{abstract}

Results and discussion: It was set that the semantic range of the term "ethnic identity of Ukrainians" is not to exhaustive (as compared to semantics of the term "identity is ethnic" in interpretation of L. Naumenko in "Encyclopedia of sociology"), that can be explained, firstly, we will remind the not sociological orientation of the polled 17th experts (that among the polled experts of the 83th, who named the teacher himself, by the scientist, by a journalist ("journalism") and philologist); secondly, although semantic range and incomplete, two basic lines qualificatory the ethnic identity of Ukrainians, in definition experts are fixed.

Conclusion: Respondents-experts are more concrete and exact, as compared to respondentsstudents. Also, it should be noted that the determination of L. Naumenko, applying on plenitude and academic approach, close on the results of the analysis of answers of respondents-experts.

Keywords: psychological, injutation, ethnic, political, media, social
Volume 2 Issue 5 - 2018

\author{
Alexander Holod \\ Department of International Academy of Pedagogical Education \\ Sciences, University of Vasily Stefanik, Ukraine
}

\begin{abstract}
Correspondence: Alexander Holod, Department of International Academy of Pedagogical Education Sciences, Doctor of Philology, University of Vasily Stefanik, Ukraine, Email akholod@ukr.net
\end{abstract}

Received: February 09, 2018 | Published: September 17, 2018

\section{Introduction}

The problem, which is discussed in the study, is rather ambivalent for Ukrainians. First, we touch the essence of the problem, later- its ambivalence. The essence of the problem of psychological intimacy of the collective (ethnic and political) identity of Ukrainians, reflected in the mass media of Ukraine during the "Patriotic War of 2014", is that:

a) First, in our opinion, modern compatriots do not have a core understanding of personal ethnic autoidentification, which means that we do not have it; besides, Ukrainians today have a two-fold (three-fold) political autoidentification, which seriously affects the formation of a single political collective identity

b) Secondly, since there is no personal self-identity of the Ukrainians, there is no also our collective identity;

c) Thirdly, the understanding of identity is rather blurred for those Ukrainians who consider themselves ready for social communication (collecting objective information, processing it, preparing for broadcasting and exchanging information, willingness to broadcast information objectively, preparing for its storage in the presence of a communicator and communicants ), but does not have the elementary skills of committing social communication inherent in objective mass media d) Fourthly, what we call social communication is now missing from the mass media audience

e) Fifthly, there is no sense of inducing the collective identity of modern Ukrainians, although certain trends in the availability of such are recorded according to the results of the studies organized and conducted by us ${ }^{1}$ and our colleagues..$^{2-5}$

We have outlined the essence of the problem of psychological inducation of the collective identity (both ethnic and partly political) of Ukrainians, reflected in the mass media of Ukraine during the "Patriotic War of 2014". The ambivalent nature of the problem is that on the one hand, in Ukraine's mass media, from February 28, 2014 (the date of the Russian invasion of the territory of the Autonomous Republic of Crimea), a clear and unambiguous record of the declaration of Ukraine's political identity (for example, in the corner of television screens the editorial offices of the TV channels posted a slogan in Ukrainian and Russian "One country - One country", the same slogan can be found on the transport: in the metro, in fixed-route taxis, in buses and trolleybuses. On the other hand, despite the clearly declared collective political identity, the mass media workers themselves (TV presenters of news programs, observers, correspondents, heroes of political talk shows, analytical programs), like the audience, do not comply with their declarations. The latter is manifested in dubious opinions about the "victory" over the interventionists in the Crimea 
and the East of Ukraine; about "fraternal" assistance of the Russian leadership to the residents of Lugansk and Donetsk regions with the help of humanitarian "convoys"; about the "purity" and truthfulness of the slogan "Ydina krayina - One Country"; about the guilt / innocence of the fighters of the special unit "Berkut"; about rightness / wrongness of V. Putin, as a policy that kills or helps Ukrainian people; about the "Jewish henchmen" of the "Kiev fascist junta, who sat in power in Ukraine." In addition, the moods of certain segments of Ukraine's population are recorded in such declarations: "We must leave this country until there is no war," "what did Poroshenko give me, what did he do for me?", "72 years of the occupation of Ukraine by the Bolsheviks could not fail affect the formation of thinking of a simple Ukrainian "," not everything was bad in the USSR "and under.

Thus, we see the ambivalent character of the problem being studied in contrasting (opposing) opinions in the mass media of Ukraine, which entails their mutation (the introduction of negative changes) both of the media themselves, and, of course, of society. Proceeding from the main provisions of the stated problem, we isolate the object of further research: the collective ethnic and political identity of Ukrainians, reflected in the mass media of Ukraine during the "Patriotic War of 2014". The subject of our scientific interest is the psychological intimacy of the collective ethnic and political identity of Ukrainians, reflected in the mass media of Ukraine during the "Patriotic War of 2014".

\section{Goal}

The aim of the research is to search for, identify and describe the signs of psychological indemnity of the collective ethnic and political identity of Ukrainians reflected in the mass media of Ukraine during the "Patriotic War of 2014".

Research methods: we turned to content analysis, which allowed us to clarify the meaning of the concepts of "ethnic identification" and "political identification", and also helped to establish the fact of the presence of signs of respondents' understanding of the essence of the analyzed concepts. We turned to the survey method in the form of a standardized questionnaire, which allowed us to be objective in our statements. The methods of generalization and abstraction did not allow us to make mistakes and allowed us to ignore the minor details that did not concern the subject of our study. When analyzing the data obtained during the survey, we used the statistical method in the form of quantitative and qualitative analysis.

\section{Methodology}

To achieve this goal, we need to carry out the following research procedures:

a) Analyze the existing scientific literature in order to find in it the results of possible studies of the collective ethnic and political identity of Ukrainians

b) In parallel, it is necessary to search for the results of possible studies of the processes of inducing the collective ethnic and political identity of Ukrainians

c) It is necessary to find the results of scientific searches concerning the identification of the characteristic features of the processes of inducing the collective ethnic and political identity of Ukrainians in the course of events that President P. Poroshenko called the "Patriotic War of 2014"

d) Clarify the meaning of the terms "indutation", "collective identity", "personal identity", "autoidentity", "inducation of the collective ethnic and political identity of Ukrainians" e) On the basis of an analysis of the results of possibly already investigated moments, close in content to our problem, to synthesize those theoretical approaches and methods that can be used as key in our study;

f) taking into account the synthesized knowledge of the degree of development (study) of the problem analyzed by us, to propose a procedure (procedure) for the practical search, definition and description of signs of psychological inducation of the collective ethnic and political identity of Ukrainians reflected in the mass media of Ukraine during the "Patriotic War of 2014"

g) Based on the results of the empirical study, formulate recommendations concerning the diagnosis of the collective ethnic and political identity of Ukrainians reflected in the Ukrainian mass media during the "Patriotic War of 2014"; except noted, to formulate recommendations aimed at improving the processes of formation of the mentioned types of identity with the help of the mass media of Ukraine.

\section{Results and discussion}

To perform the first research procedure, we need to analyze the existing scientific literature in order to find in it the results of possible studies of the collective ethnic and political identity of Ukrainians. Among the known studies of identity, we note the following. ${ }^{6-9}$ To eliminate the possible discrepancies in the meaning of the terms to which we refer, we will clarify their meanings. Transforming the definition of identity proposed by AN Krylov, the term "ethnic identity" means "the property of the human psyche in a concentrated form to express for him how he conceives his belonging to various" ethnic, "social, national, professional, linguistic, political, religious, racial and other groups or other communities, or identifying oneself with this or that person, as an embodiment of the inherent properties of these groups or communities ".${ }^{10}$ We do not identify the terms "ethnic" and "national", and therefore we propose to insert the term "ethnic" in the definition of NA Krylov. In our understanding, ethnicity should be considered as belonging to an ethnos, which is traditionally defined as "a historically established stable set of people, ${ }^{11}$ united by common objective or subjective signs ... (language, culture, territory of residence, self-awareness). To the subjective features of such a historically established stable set of people, for example, T. Zherebilo, includes

a) The specific characteristics of culture;

b) A common language, which is one of the main ethnosocial features;

c) Characteristic features of the psyche;

d) Self-awareness;

e) Self-name (auto-name). Let's note, after the author, that "ethnoses, being at different stages of development, are represented by genera, tribes, nationalities, nations". ${ }^{12}$ The thought of TV Zherebilo is confirmed by O. Maiboroda, who believes that "the population of the state becomes a nation when it adopts a common system of political, legal, cultural values, that is, when the population becomes a consolidated organism". ${ }^{13}$

LI Naumenko defines ethnic identity as "the result of an emotionallycognitive process of comprehension of ethnicity, identification of the individual with representatives of his ethnos and isolation from other ethnoses, as well as a deeply personal experience of his ethnicity". ${ }^{14}$ Not all researchers defend the idea of the existence (functioning) of 
the ethnic identity of Ukrainians. For example, M. Mogilyansky in 1912 wrote: "Without the national intelligentsia, there is no nation, but there is only an ethnographic mass, the appearance of a nation". ${ }^{15}$ It is difficult for us to agree with the statement of M. Mogilyansky, since a hundred years after the publication of the cited words, history confirmed a slightly different fact: the nation of Ukrainians continued the process of formation, self-identification during the 2004 Orange Revolution and the 2013-2014 Dignity Revolution. However, M. Mogilyansky's opinion was not the same. For example, P. Stebnitsky in 1917 argued that "there is no nation in Ukraine", it is "in an embryonic state". ${ }^{16}$ The author insisted that the nation in Ukraine can be formed exclusively by the intelligentsia. However, at the same time, P. Stebnitsky criticized the Ukrainian intelligentsia for disunity. ${ }^{16}$ According to Yu Velyachey. ${ }^{17}$ The researcher believed that the sign of a historical nation is the presence not only of her own state, but also the preservation of her elite, higher social strata that act as carriers of political consciousness and elite culture. ${ }^{17}$ Interesting, in our opinion, should be considered P. Stebnitsky's assertion that the Ukrainian nation is "national-problem people" ${ }^{16}$ Perhaps that is why the term "representatives of the organisational Ukrainian people" is found in the works of the first president of the Ukrainian People's Republic (UPR). ${ }^{18}$ It should be noted that M. Hrushevsky does not call the Ukrainians "Ukrainians", but only hints that such a nation may begin to form, calling the representatives of Ukraine "Ukrainian nationality" (in the Ukrainian language "Ukrainian people") at the beginning of the 20th century. Although it should be noted that in 1919 M. Hrushevsky uses the ethnonym "Ukrainians" in the title of one of his articles (see Hto soi Ukrainians i chogo vonyi uchit ' ${ }^{18}$ An analysis of several works by politicians and researchers of the early 20th century shows that:

1. The ethnonym "Ukrainians" is not used by all politicians and publicists, as well as by researchers of Ukrainian identity

2. The emergence of Ukrainian ethnic identity was associated, first of all, with the solidarized movement of the Ukrainian intelligentsia.

A century later, in an independent state of Ukraine, an interesting study, in our opinion, was carried out, confirming some of the conclusions and trends that we reported earlier. We have in mind the work of T. Voropaeva "Forming the collective identity of citizens of Ukraine: the value dimension". ${ }^{19}$ Analysis of the results of the research by T. Voropaeva allowed us to state the following:

1. the processes of globalization stimulate the globalization tendencies, which leads to the formation of qualitatively different "mechanisms" of the collective identity of citizens of Ukraine

2. collective "identification should be considered as a process included in the whole life activity of the subject"

3. "the concept of" collective identity "covers a certain collective" We "of a particular community (regional, religious, ethnic, national, continental, etc.)"

4. collective identity, according to T. Voropaeva, should be considered "a common sense of belonging to a certain community or society"

5. collective identification is firmly connected with the identification of the personal

6. the process of forming a collective identity is accompanied by the construction of a "definite collective image of this community, with which the members of this community identify themselves"
7. from the point of view of T. Voropaeva, "collective identities can be considered as communicative constructs, discursive facts that need to be interpreted correctly, revealing those sociocultural horizons that are hidden behind them"

8. the author believes that "the crisis of collective identity is always associated with the leveling of traditions, the disintegration of common cultural memory, the rejection of authentic symbolic and value-semantic cultural systems, the destruction of the system of collective historical experience and common ideas". ${ }^{19}$

Practical study of collective identity was carried out by the author in the period from 1991 to 2011 with the support of several international scientific projects of the Center for Ukrainian Studies of Kyiv National Taras Shevchenko University ("Ukrainian National Idea: Theoretical and Empirical Aspects", "Socio-Psychological and Regional Aspects of Formation of National Identity" citizens of Ukraine as a factor of state construction ";", Transformation of national identity: historiosophical, culturological social and psychological aspects ", etc..), which were supported by the Foundation" Revival ", the Friedrich Ebert Foundation, the Foundation for Basic Research of the Ministry of Education and Science of Ukraine and the Association of Ukrainian Banks. The study was subject to "gender, age, professional, religious, ethnic, metaethnic, local, regional, national, European (or continental), planetary, post-Soviet and other types of identity of citizens of Ukraine living in different regions of the country." According to T. Voropaeva, "39,400 respondents from 18 to 87 years old were studied". ${ }^{20-22}$

As Voropaeva testifies, "for studying the transformation of different types of identity," she and her colleagues used the "M. Mehn-Karta-T. McPartland technique" Who Am I? ", The adapted methodology of the" Sinerella Identity Scale". In addition, "to study the axiological features of the formation of the collective identity of Ukrainian citizens," the researchers turned to "the method of studying the value orientations of M. Rokich," and used Schwartz's "theoretical and empirical approach". ${ }^{23}$

The authors of the study came to the following conclusions:

I. in the post-Soviet space, "the overthrow of post-Soviet identity" was recorded (in the period from 1991 to 1999)

II. also recorded "the increase in ethnicity (1991-1999) and religious (2001-2010) identity"

III. marked "the transformation of the Slavic identity (1999-2010)

IV. regional identity has been strengthened (2006-2009)

V. the prestige of national identity has increased (2001-2008)

VI. European identity was established (1999-2008).

According to the results of the research conducted, Voropaeva concludes that "the subject (both individual and collective) is the center of value and meaning relations within the framework of the national community." The author is confident that "the basic values of Ukrainian culture significantly influence not only the hierarchy of the entire structure of collective identity, but also the integration of collective identity into an integral system." Interesting for us is the conclusion of T. Voropaeva about "the preservation of basic values and the development of a collective identity," which, in her opinion, is "an important condition for the existence and development of the Ukrainian nation and Ukrainian national culture in the context of globalization". ${ }^{19}$ Discussion of the problem of psychological integration of the collective identity of Ukrainians during the "Patriotic War of 2014", reflected in the mass media of Ukraine, calls 
for the use of the term "political identity". In working order, further, a political identity will be called "the property of the human psyche in a concentrated form to express for him how he conceives his belonging to different" political groups and the embodiment of their properties in the models of behavior of the individual.

However, the meaning of the term "political identity" is interpreted differently by specialists. For example, IN Timofeev in his Ph.D. thesis "Political Identity of Russia in the Post-Soviet Period: Alternatives and Trends" (2006) defines political identity from the perspective of the three components. According to the author, "within the first component, political identity is defined as a set of political principles serving as the normative basis for the citizens' awareness of their political community, the basis for answering the question" Who are we? ". The second component assumes "a set of ideas that set the unique essence of a particular state through its correlation with the actual Other in the logic of the opposition" We are They ", and also through the marking of state borders (mostly symbolic)." I.N. Timofeev is inclined to think that within the third component, political identity should be considered "as a set of ideas about the past of the political community, historical events that are significant for citizens of the country and their awareness of their political community". ${ }^{24}$

Considering political identity in the conditions of a nation-state of a modern type, the author proposes to define such as "purposeful actions of the state for its formation" when performing "the function of integration of the political community, legitimization of the political regime, mobilization of citizens". It is difficult not to agree with IN Timofeev that "the purposeful construction of political identity is limited by the historical context, political traditions, culture and other factors", ${ }^{24}$ which is vividly illustrated by the processes of psychological inducation of the collective (ethnic and political) identity of Ukrainians during the "Patriotic War of 2014", reflected in the mass media of Ukraine.

To identify similar and different characteristics in the definitions of the two terms we use in the study ("ethnic identity" and "political identity"), we turn to the analogy method. The analysis of indicators shows that in working definitions of two key terms used in our study, in $50 \%$ of cases, coincidences were found, in $50 \%$ - differences. The ratio noted above supports the opinion of both the presence of differences and similarities in the semantics of terms. It follows that in the future we distinguish between terms based on "ethnic" and "political"; "Identification (as an embodiment)" and "incarnation"; "Themselves" and "their properties"; "With this or that person" and "in the models of the behavior of the individual". In carrying out the second research procedure, we turn to the search for the results of possible studies of the processes of inducing the collective ethnic and political identity of Ukrainians. After unsuccessful attempts to find the results of studies of people close to the problem, the one we are analyzing has the right to state the complete absence of direct (corresponding to the stated subject) research. We did not find the indirect ones (analyzing this or that aspect of our problem) studies either. Hence, we conclude that it is impossible to perform the second research procedure planned by us in the study methodology. According to the third procedure, our research involves the search for the results of scientific intelligence related to the identification of the characteristic features of the processes of inducing the collective ethnic and political identity of Ukrainians in the course of events reflected in the media, which President P. Poroshenko called the "Patriotic War of 2014".
Earlier, discussing the trends of revolutionary fascism in the actions of the militants of the so-called "LNR" ("Lugansk People's Republic") and the "People's Republic of Donetsk", reflected in the video-television technologies of the media and directly related to the Patriotic War of 2014, ${ }^{25}$ we paid attention to the fact that the inducing of models of the behavior of society occurs with the active assistance of technologies of television mass media and video communication technologies used in YouTube. Our thoughts that the unfulfilled hopes of the revolutionary masses in Ukraine led to the inducing of a society whose markers were skillfully replicated in the mass media of Russia and Ukraine, as well as in the media of the world, and can be applied in a productive way in analyzing the processes of psychological inducation of the collective and political) identity of Ukrainians, reflected in the mass media of Ukraine during the "Patriotic War of 2014". Discussing the problem of mass inducing as a stimulus for protest activity in accordance with the analysis criteria proposed in the theory of ${ }^{26}$ we concluded that during the events of the autumn of 2013 and the spring of 2014, which took place on the Independence Square in Kiev (the opposition of the revolutionary masses and the power of V. Yanukovych, which caused more than a hundred deaths and more than a thousand people wounded), the mass of the masses takes place according to the female type and has characteristic signs (technologies) of influence on society.

In the study, ${ }^{27}$ we studied the markers of mass communication intuition not in the conditions of the Patriotic War of 2014 and came to the conclusion that society suffers from mass communication imputation due to the appearance of indutated mutants. Indeed, the impact on the society of mass communication, which has already been indulged, gives rise to a phenomenon that, in the working order, we called "the inducation of the intuition." Individuals who make up a society that suffers from this phenomenon are transformed into indutated mutants in this case. Moreover, the intuition of the mutation occurs with the most active participation of the mass media (first of all, television media). Unfortunately, during the implementation of the third research procedure aimed at finding the results of scientific intelligence related to the identification of characteristic features of the processes of inducing the collective ethnic and political identity of Ukrainians in the course of events reflected in the media, which President P. Poroshenko called "The Patriotic War of 2014 ", We did not find any. The latter allows us to state the conclusion that now there are no similar studies.

The fourth research procedure suggested clarifying the meaning of the terms "indutation", "collective identity", "personal identity", "autoidentity", "inducing the collective ethnic and political identity of Ukrainians". Relying on the theory of the societal induction proposed by us earlier (see),$^{28}$ we interpret mutation as introducing changes in the worst side in the model of society's behavior. Under collective identity, we, after Voropaeva, understand "a common sense of belonging to a certain community or society". ${ }^{19}$ In order to interpret the term "personal identity" ("autoidentity") we refer to the concept of "identity", which has the semantics "the property of the human psyche in a concentrated form to express for him how he conceives his belonging to various social, national, professional, linguistic , political, religious, racial and other groups or other communities, or identifying oneself with this or that person, as an embodiment of the inherent properties of these groups or communities ". ${ }^{29}$ In the understanding of the term "personal identity" we introduce the same meaning as in the understanding of the term "identity" and 
"autoidentity". The term "inducing the collective ethnic and political identity of Ukrainians" is interpreted as introducing negative changes in collective representations (behaviors) about belonging to ethnic and political groups or communities, or introducing negative changes in those representations (patterns of behavior) that allow the community to be identified themselves with common ethnic or political characteristics. In addition to the listed and interpreted terms in the study, we use the term "Patriotic War of 2014", which on August 24, 2014, the President of Ukraine, Peter Poroshenko, used in his speech in Kiev on the parade on Independence Day of Ukraine. The latter literally said: "The events of recent months are the Patriotic War of 2014". ${ }^{30}$ Since in the scientific literature the term is not used, we address it only in working order, without an attempt to introduce it into scientific use.

The fifth research procedure presupposed "on the basis of an analysis of the results of possibly already investigated moments, close in content to our problem, to synthesize those theoretical approaches and methods that can be used as key in our study." The analysis of the results of the research by ${ }^{31}$ gave us grounds for isolating the theoretical approach to the study of psychological collective (ethnic and political) ) the identity of Ukrainians, reflected in the mass media of Ukraine during the "Patriotic War of 2014". This approach was hypotheticodeductive, the essence of which we describe as the promotion of the hypothesis (hypothesis) and his (her) subsequent proof with the deduction method. The assumption in our study was the statement that the process of psychological inducation of the collective ethnic and political identity of Ukrainians, reflected in the mass media of Ukraine during the "Patriotic War of 2014", has a number of signs, among which we classify three groups.

\section{Psychological intimacy of ethnic identity in the mass media (objective signs):}

i. use in the media of two languages (Ukrainian and Russian), which leads to a mutual distortion of the norms of the literary language and influences the formation of ethnic and political identity

ii. the introduction and sometimes planting with the help of television media elements and cultural stereotypes of an alien Ukrainian ethnic identity (for example, in the East and in the Autonomous Republic of Crimea - the implantation of elements of Russian culture in the North and South of Ukraine - the introduction of elements of Russian culture, in the West and South-west Ukraine - the introduction of elements of Polish, Romanian, Moldovan culture)

iii. the production of constant media alarms for Ukrainians that the territory of their residence is susceptible to an attack by a neighboring power, as a result of which there is nervousness in society, tension; at first glance, seemingly unmotivated microsocial conflicts demonstration in mass media of frequency cases of distortion of forms of collective consciousness; in the meaning of the term "collective consciousness" we introduce the meaning proposed by E. Durkheim: "the spiritual unity of society, which is not a simple sum of individual consciousness, existing independently of them in the form of social factors (customs, morality, law, traditions, knowledge), which has a strong influence on individual consciousness; collective consciousness creates a moral social environment that forces people to adopt the modes of action and thinking that are prevalent in a given society; forms of collective consciousness: collective representations, collective feelings ". 32

\section{Psychological intimacy of ethnic identity in the media (subjective signs)}

i. hypertrophied demonstration in the media of specific features of Ukrainian culture (for example, in the newspapers "Segodnya", "Vesti", in the television programs of the "Inter" TV channel: in the telecasts of the "Podrobnosti" program, the telecast "Touching Everyone")

ii. biased ignoring of the use of the Ukrainian language, which is one of the main ethnosocial signs of the identity of Ukrainians

iii. deliberate exploitation of the characteristic features of the psyche of Ukrainians (patience, individualism, disregard for the collective)

iv. humiliation of self-consciousness (personal); by selfconsciousness ${ }^{33}$ we mean "a psychic phenomenon, a person's consciousness of himself as a subject of activity, as a result of which the person's ideas about himself are added to the mental" image of self "(Self-Consciousness, 2015); 5) the presence of a humorous connotation in the self-name of the representatives of the nation (ethnonym): "dill", "khokhly", "ukry" and pod.

\section{Psychological inducation of political identity in the media:}

i. "blurring" of the "set of political principles" (the term of I. Timofeev), which, according to the author, serve as the "normative basis for the citizens' awareness of their political community, the basis for answering the question" Who are we? “,

ii. the presence of "a set of representations, by the definition of IN Timofeev, who set" the unique essence of a concrete state through its correlation with the actual Other in the logic of the opposition "We are They", and also through the marking of state borders (mainly symbolic) »;

iii. the existence of differentiation (sometimes polar) as a totality, according to IN Timofeev, "representations about the past of the political community, historical events that are significant for citizens of the country and their awareness of their political community. ${ }^{24}$

iv. The sixth research procedure assumed, taking into account the synthesized knowledge of the degree of development (study) of the problem analyzed by us, to propose a procedure (procedure) for the practical search, definition and description of signs of psychological inducation of the collective ethnic and political identity of Ukrainians reflected in the mass media of Ukraine during the Patriotic War 2014".

\section{Methodology of research}

a) The study suggested a number of such procedures when applying the following methods of scientific knowledge

b) a survey of experts

c) a survey of student respondents

d) content analysis of publications in the press, on television and on websites of Internet portals

e) a comparative analysis of the results of a survey of experts and student respondents 
f) deductively inductive analysis of the results of applying the analogy method and the formulation of conclusions throughout the study.

Next, we describe in detail the research procedures.

1. The survey (in the form of interviews and interviews, as well as a questionnaire offered to respondents on the pages of Facebook and Facebook social networks), 15 experts (teachers - candidates and doctors of science teaching the disciplines at Kyiv National Taras Shevchenko University and Kyivan National University National University of Culture and Arts for teaching students in the field of "Journalism", "Advertising and Public Relations." "Publishing and Editing"); during the interview and conversation, the experts were asked three questions: 1) What do you understand by the term "ethnic identity of Ukrainians" and "political identity of Ukrainians"? 2) What is "collective identity" and "personal identity"? 3) Has the identity of Ukrainians changed in the best direction (mutation) or for the worse (the mutation) in the media coverage of the antiterrorist operation (ATO) in the East of Ukraine in 2014?

2. Survey of respondents (in the form of a standardized questionnaire and a task proposed on the pages of social networks "Facebook" and "VKontakte" and on paper): 145 respondents-students participated in the study, who answered the following 17 questions (pp. 1-14, 17) of the standardized questionnaire, and also completed two tasks (15-16):

i. What do you mean by the terms "ethnic identity of Ukrainians" and "political identity of Ukrainians"?

ii. What is "collective identity" and "personal identity"?

iii. Has the identity of Ukrainians changed during the media coverage of the antiterrorist operation in the East of Ukraine in 2014 and in what has changed for the better (mutation) or for the worse (immatation)?

iv. What newspapers and magazines do you consider mutational (who made positive changes) or indutational (which brought negative changes) in the formation of the ethnic and political identity of Ukrainians during the coverage of ATO events in 2014)?

v. Which TV programs do you recognize as mutational (who made positive changes) or indutational (which introduced negative changes) in the formation of the ethnic and political identity of Ukrainians during the coverage of the events of the ATU in 2014)?

vi. What sites do you recognize as mutational (who made positive changes) or indutational (who introduced negative changes) in the formation of the ethnic and political identity of Ukrainians during the coverage of ATO events in 2014)?

vii. What are the five signs of mutation (improvement) or inducing (worsening) the process of formation of ethnic and political identity of Ukrainians during media coverage of ATO events in $2014 ; 2.8$. Collective ethnic and political identity of Ukrainians during media coverage of ATO events in 2014: a) was formed; b) not formed; c) it is difficult to answer; d) it is not.

3. Content analysis of publications in the press, on websites and television broadcasts on television was carried out according to several parameters set forth below:
Content analysis of publications in the press: 200 publications of journalistic materials were placed in the archives of the websites of such newspapers: Vesti, Today, Zerkalo Nedeli; magazines: "Correspondent", "Focus"; «Forbes Ukraine». The content analysis of the texts of the broadcasts on television was made from the calculation: "TSN" on the TV channel "Studio 1 + 1", "Details" on the "Inter" TV channel, "Vikna" on the STB channel, "Shuster Live" on the TV channel "112", "Groshy" on the TV channel "Studio 1 + 1", "Affects Everyone" on the "Inter" TV channel. Content analysis of publications on the sites: "Lb" (Left Bank) - Internet portal; "Ukrainskaya Pravda" is an Internet portal; Depo.ua is an independent Ukrainian online publication; "Censor.net" - an Internet portal; "Obozrevatel.ua" - an Internet portal; "Main.ua" is an Internet portal.

\section{The discussion of the results experts}

The next research procedure for us was a comparative analysis of the results of the survey of 17 experts (or $100 \%$, see Appendix A) and 145 student respondents (or 100\%, see Appendix B). Among the experts of men there were $7(41 \%)$ and women - $10(59 \%)$. Geographical representativeness of the interviewed experts was 5 cities of Ukraine, in particular: Kyiv - 9/53\%; Lviv - 2/12\%; Krivoy Rog - $1 / 6 \%$; Vinnitsa - $2 / 11 \%$; Donetsk - 3/17\%. The average age of the experts surveyed was 45 years. Professional orientation of experts had such a relationship (in quotation marks the autonym name of the respondent is given in the original language): philologist - $2 / 12 \%$, programmer - $1 / 6 \%$, "naukovets" - 3/18\%; «Викладач», the teacher - $5 / 29 \%$; manager $-1 / 6 \%$, journalist $-2 / 12 \%$, journalism - $2 / 12 \%$, university employee - $1 / 6 \%$. Experts' answers to question 1 "What do you put in the meaning of the term" ethnic identity of Ukrainians? "Were distributed in this way (quotation marks the opinion of the respondent in the original language, the letter of the alphabet denotes the response codes). An analysis of the answers of the expert respondents to question 1 "What do you mean by the meaning of the term" ethnic identity of Ukrainians "?" Allowed us to state the following features:

i. two respondents' answers ("conscious desire to be Ukrainian" and "belonging") had the highest rates ( $29 \%$ each);

ii. the remaining 7 responses had a $6 \%$ each; We attributed the following to such answers:

iii. "common features inherent in the people", "territory, language, culture, mentality", "origin", "hibne", "problem problem", "march", "spivvidesnennya z Ukrainsky." Thus, taking into account the frequency options of experts' answers to question 1 , we found that the ethnic identity of Ukrainians should be considered a "conscious desire to be a Ukrainian" and "belonging to the Ukrainian."

\section{The students}

Sociometric data allow us to state that $145(100 \%)$ of student respondents took part in the survey, including $17(11.7 \%)$ men and $128(88.3 \%)$ women, which, in our view, should be taken into account when interpreting the obtained indicators. Respondents, students on the basis of nationality were distributed as follows: Ukrainian 141/97\%; Jew - 1 / 0.7\%; Greek - 1 / 0.7\%; "Sloveninka" - 1 / 0.7\%; Armenian - $1 / 0,7 \%$. The geographical representativeness of the survey was presented by seventeen cities of Ukraine in such a ratio: the respondents living in Kiev were $85.4 \%$, in Donetsk - 6\%, in Vinnitsa $-7.6 \%$, and $0.07 \%$ were the opinions of respondents living in such settlements: Yenakiyevo (Donetsk region), Kharkov, Zaporozhye, Uman, Dneprodzerzhinsk, Ternopil, Yalta, Chernigov, Kagarlyk, 
Fastov, Uzly and Borodyanka (Kiev region). The average age of the respondents was 19.2 years, in $96 \%$ of cases the occupation of respondents was designated as "student", "study"; in $4 \%$ of cases the occupation was recorded as: "journalist", "philologist", "historian", "translator", "laboratory assistant", "creativity".

To the question "What do you put into the meaning of the term" ethnic identity of Ukrainians? "We received answers that were grouped into 14 such variants and in the working order designated them with the letters of the Russian alphabet (the answers are presented in the original languages - Russian and Ukrainian): Analysis of the data interpreted by us allowed us to state the presence of the following features of the answers of 145 student respondents to the question "What do you mean by the term" ethnic identity of Ukrainians "?":

a) the highest $(28.4 \%)$ indicator was recorded for the answers that we combined into the group "Territory, language, culture, mentality; історія, традиції »;

b) to the high $(15.9 \%)$ indicator we attributed the answers of the group with the conditional name "Conscientious desire to be a Ukrainian, self-surrender, the attitude of Ukrainians to themselves; love of one's nation ";

c) the next place in the conditional rating of frequency indicators is $11.8 \%$ (group of answers with the conditional name "Belonging");

d) the indicator $10.4 \%$ has a group of reactions called "Failure";

e) a group of answers with a working title "The general idea, the same views, spilnie ideas; the similarity of Ukrainians with each other; this is an assessment of all adequately each Ukrainian in each other "fixed indicator of $9.7 \%$;

f) other responses had such indicators: $8.4 \%$ - "Special attention to the people, for some you can visit the Ukraine; Identification of oneself with other representatives of one's own self "; $6.9 \%$ - "The origin, march, root, genetics"; $4.9 \%$ - "Ukrainians are one whole; expression of Ukrainians as an original people, Ukrainians are a single nation ";

g) as a low-frequency $(0.7 \%)$, an indicator was determined that was recorded for the remaining 5 groups of answers, namely: "Spivvidesnennya v Ukrainsky", "Nationality", "Interrelation of Intercultural Development of Ethnic Groups", "Tolerance to Each Other" , "The desire of Ukrainians to be independent"

Taking into account the fixed features, we formulated the conclusions concerning the quality of the answers of 145 student respondents to the question "What do you mean by the term" ethnic identity of Ukrainians "?".

1. A third of the interviewed students surveyed came to the opinion that the term "ethnic identity of Ukrainians" should be understood as "territory", "language", "culture", "mentality", "history", "traditions". Every sixth respondent believes that the ethnic identity of Ukrainians should be considered a conscious desire to be a Ukrainian, the presence of self-awareness, a certain attitude of Ukrainians to themselves and a love for their nation. Every seventh respondent defines as an obligatory attribute ethnic identity of Ukrainians belonging to the "Ukrainian" nationality.

2. Proceeding from the fact that the sum of the first three positions in the frequency rating of respondents 'answers was expressed by $56.1 \%$ (more than half of $100 \%$ of respondents), we formulated a working definition of ethnic identity of Ukrainians (for the mentioned $56.1 \%$ of respondents' answers). The essence of this definition boils down to the fact that the ethnic identity of Ukrainians should be considered a community of people united by one territory, language, culture, mentality, history and traditions, with a conscious desire to be a Ukrainian; the presence of such a community of self-awareness, a certain attitude of Ukrainians to themselves, the love of Ukrainians for their nation, belonging to the "Ukrainian" nationality.

The working definition of the term "ethnic identity of Ukrainians", formulated by us on the basis of the analysis of the opinions of 145 student respondents, differs from the definition that the "experts" suggested, and at the same time is close in its semantics to the one close to social communications definition, proposed in LI Naumenko in "Sociology. We compared the definitions of LI Naumenko's "ethnic identity" and the working definition of the term "ethnic identity of Ukrainians", formulated on the basis of an analysis of the answers of respondents-experts and student respondents. In the analysis of the indicators, we compared the syntagms of Definition 1 (Naumenko, 2018): for $100 \%, 5$ syntagmas were accepted), Definitions 2 (17 expert respondents: 2 syntagmas were taken for $100 \%$ ) and Definition 3 (145 respondents -Students: 10 per cent were accepted for 100\%). Moreover, Definition 1 concerned the definition of the term "ethnic identity", definitions 2 and 3 revealed the meaning of the term "ethnic identity of Ukrainians".

\section{The analysis allowed us to fix the following features:}

a) in Definition 1 (Naumenko, 2018), we extracted 5 syntagmas $(100 \%)$, of which $1(20 \%)$ coincided with the syntagma in Definition 2, from which it follows that $80 \%$ of the syntagmas did not coincide;

b) when comparing definitions 1 (Naumenko, 2018) and 3 (respondents-students), we found that one (20\%) syntagma coincides, which indicates an $80 \%$ mismatch of other syntagmas in two definitions;

c) in Definition 2 (experts) - two syntagmas (100\%), of which only $1(50 \%)$ coincided with the syntagma of Definition 1 ; consequently, one more $(50 \%)$ syntagma does not coincide with the syntagma of Definition 1 ;

d) the comparison of syntagmas in the definition of 2 (total $2 / 100 \%$ of the syntagma) and the definition of 3 (total - 10/100\% of the syntagmas) made it possible to state $2(20 \%)$ coinciding syntagmas and, accordingly, 8 (80\%) - non-coincident;

e) analysis of the definition of 3 (total - 10/100\% of the syntagmas) with the definition of 1 (total $-5 / 100 \%$ of the syntagmas) showed that one $(1 / 10 \%)$ coincidence and, accordingly, $9 / 90 \%$ - mismatches;

f) the search for coincidences between the syntagmas of the definition 3 (total $-10 / 100 \%$ of the syntagmas) and the definition of 2 (total $-2 / 100 \%$ of the syntagmas) gave grounds to assert that such there are $2 / 20 \%$ and, accordingly, $8 / 80 \%$ - coincidences not visible.

Taking into account the six features listed above, we came to the conclusion that the definition 1 of the term "ethnic identity") and the definition 2 of the term "ethnic identity of Ukrainians" (respondents) have a ratio of 5: 2 , which is expressed by the coefficient 2.5. In turn, the ratio of the number of syntagmas in Definition 2 and Definition 1 is the reverse, which is expressed as $2: 5$, or by a factor of 0.4 . Comparing the aforementioned relations 5: 2 (2.5) and 2: 5 (0.4), we state: 
1. The definition of the term "ethnic identity", proposed by LI Naumenko (Naumenko, 2018), has a number of syntagms that is 2.5 times the number of syntagmas in the definition of the expert respondents;

2. The definition of the term "ethnic identity of Ukrainians" (formulated on the basis of an analysis of the answers of expert respondents) made it possible to fix the coincidence ratio (equal to 0.4 ) with the definition of the term "ethnic identity". ${ }^{14}$

Thus, the semantic range of interpretation by respondentsexperts of the term "ethnic identity of Ukrainians" is not exhaustive (in comparison with the semantics of the term "ethnic identity" in interpretation (Naumenko, 2018), which can be explained, firstly, not by the sociological orientation of the polled 17- (recall that among the surveyed experts $83 \%$ of those who called themselves a teacher ("vicladach" - Ukrainian language), a scientist ("scientist" Ukrainian language), a journalist ("journalism") and a philologist) secondly, although the semantic range zones and is not complete, the two main features that determine the ethnic identity of Ukrainians in the definition of the experts reported. Comparison of Definition 2 (experts) and Definitions 3 (students) has a different number of syntagms, which is fixed by the ratio $2: 10$, or 0.2 , whereas the inverse ratio has the exponent 5 . The mentioned relationships, in our opinion, allow us to state, firstly, that of the large (10) number of syntagms in the definition of the student respondents, only 2 correspond to the definition given by the expert respondents and only one syntagma given in the definition of LI Naumenko (Naumenko, 2018). We believe that the definition of student respondents is redundant, since students have not yet fully realized the meaning of the term "ethnic identity of Ukrainians" and "blurry" determine its meaning by means of those syntagms that they met when interpreting terms, for example, "ethnos", "Ethos", "nationality", "ethnic", "national".

\section{conclusion}

Thus, the analysis of the definitions of respondents (experts and students) and the definition of LI Naumenko in interpreting the terms "ethnic identity of Ukrainians" and "ethnic identity", respectively, allow formulating the conclusion that the respondents-experts are more specific and accurate, in comparison with respondents-students. It should also be noted that the definition of LI Naumenko, claiming for completeness and academicity, is quite close to the one that was formulated by us based on the analysis of the answers of the expert respondents.

\section{Acknowledgments}

None.

\section{Conflict of interest}

The author declares there is no conflict of interest.

\section{References}

1. Holod OM. The main signs of mass communication imputations. Berlin NETZ. German Russian online portal. 2011.

2. Budyul LV. Features of identification of protest image in social networks Communication technologies: sciences. Journ. 2014;6:166-176.

3. Ostrovskaya NV. Technology "Creating favorable conditions for the participant's self-presentation" in the political television talk show Communication technologies: science. Journ sci Ed O M Kholod. KNUKiM; 2014. p. 76-86.

4. Pokalchuk O. The entire Ukrainian people are now in the process of becoming a political nation. 2018.
5. Shilova VV. Modeling the function of communal technology on the telebachen: principle, structure, functions. In: Gorodenko L, Zrazhevska N, Ishchuk N, editors. USA: Georgia Institute of Technology; 2014. p. 233-264.

6. Helner E. Nation and Nationalism: National Identity. Kharkiv: Step; 2002. 316 p.

7. Smith Anthony D. National Identity. K: Fundamentals; 1994. 390 p.

8. Sofronova LA. About Identity Problems: Culture through the Prism of Identity. M: Indrik; 2006. p. 8-24.

9. Samuels E, Shorter B, Plot F. Identity. In: Young K, editor. Critical Dictionary of Analytical Psychology. Moscow: MNPP "ESI". 1994. p. 58-59.

10. Krylov AN. Evolution of Identities: the crisis of industrial society and the new self-knowledge of the individual. M: Publishing house NIB; 2010. 272 p.

11. Ethnos. 2018.

12. TV Zherebilo, Draw TV Etnos. Terms and concepts of linguistics: General linguistics. Sociolinguistics: Dictionary. Nazran: LLC Pilgrim; 2011. $20 \mathrm{p}$.

13. Mayboroda O. Ukrainian elite: with the people or in itself. Homeland. 1998. p. 11-12.

14. Naumenko LI. Ethnic Identity: Encyclopedia of Sociology. 2018.

15. Mohyliansky M. Ukrainian Problem. Petrograd; 1916.8 p.

16. Stebnicki P. Selected Works: emphasis and introduction. K: Tempora; 2009. p. 17-18.

17. Telyachiy Yu. Ukrainian literary and artistic intelligentsia in the national cultural exodus (1917-1921). Telyachy Ternopil: TZOV, Terno graph; 2014. p. 283-302.

18. Hrushevsky MS. What are the Ukrainians and what they want? 1917. $16 \mathrm{p}$.

19. Voropayeva T. Transformation of the National Identity of Ukrainian Citizens (1991-2001). Kyiv University; 2015. p. 12-17.

20. Voropaeva T. Transformation of the National Identity of Ukrainian Citizens (1991-2001). Series Ukrainian Studies; 2002. p. 12-17.

21. Serhiychuk V. Transformation of national identity: historiosophical, cultural and socio-psychological aspects. Foundation for Fundamental Research; 2005. p. 24-53.

22. Voropaeva TS. Features of the formation of national and European identity of citizens of Ukraine. Zhitnigor B, Godvint L, Kupreychik A, et al, editors. Problems and tendencies of modern society development. Materials of the IX $X^{\text {th }}$ International Scientific and Practical Conference. Odessa: In Press; 2011. p. 33-35.

23. Schwartz SH. Universals in the structure and content of values: Theoretical advances and empirical tests in 20 countries. In: Zanna MP. Advances in Experimental Social Psychology. 1992;25:1-65.

24. Timofeev Ivan Nikolaevich. The political identity of Russia in the postSoviet period: alternatives and trends: polit. sciences; specialist. Political institutes, ethnopolitical conflictology, national and political processes and technologies. 2006. 202 p.

25. Holod OM. Television and Video Communication Technologies of Revolutionary Fascism as Society's Immutation. Berlin NETZ, GermanRussian online portal; 2018.

26. Holod OM. Immutation of mass yak stimulus protostnoC C-activity (criteria of analysis on the theory of S. Moscovichi). Pereyaslav Khmelnitsky: 2014;17:275-292.

27. Kholod OM. Transformatsiya syspil'stva yk base category in the process of transforming television telemedia. Mediatransformatsii: rik perviy: 2014; p. 26-48. 
28. Holod M. Theory of Incompatibilities: Monograph. KMU; 2011. 13 p

29. Erickson E. Identity: youth and crisis. Moscow: Flint; 2006. 352 p.

30. Poroshenko. The events of the last months are the Patriotic War of 2014 2014.
31. Voropaeva T. Formation of Collective Identity of Ukrainian Citizens: Value Measure. Scientific article; 2013. p. 37-40.

32. Encyclopedia of Sociology. Collective Consciousness; 2009.

33. Self Consciousness. 2014. 